\title{
Electrochemical Detection of NT-proBNP Using a Metalloimmunoassay on a Paper Electrode Platform
}

\author{
Nicole E. Pollok, Charlie Rabin, Charuksha T. Walgama, Leilani Smith \\ Department of Chemistry, The University of Texas at Austin, Austin, Texas 78712-1224, United \\ States \\ lan Richards, \\ Interactives Executive Excellence LLC, Austin, Texas 78733, United States \\ Richard M. Crooks \\ Department of Chemistry, The University of Texas at Austin, Austin, Texas 78712-1224, United \\ States;
}

\begin{abstract}
In this paper, we demonstrate an electrochemical method for detection of the heart failure biomarker, N-terminal prohormone brain natriuretic peptide (NT-proBNP). The approach is based on a paper electrode assembly and a metalloimmunoassay; it is intended for eventual integration into a home-use sensor. Sensing of NT-proBNP relies on the formation of a sandwich immunoassay and electrochemical quantification of silver nanoparticle (AgNP) labels attached to the detection antibodies (Abs). There are four important outcomes reported in this article. First, compared to physisorption of the detection Abs on the AgNP labels, a 27-fold increase in signal is observed when a heterobifunctional cross-linker is used to facilitate this labeling. Second, the assay is selective in that it does not cross-react with other cardiac natriuretic peptides. Third, the assay forms in undiluted human serum (though the electrochemical analysis is carried out in buffer). Finally, and most important, the assay is able to detect NT-proBNP at concentrations between 0.58 and $2.33 \mathrm{nM}$. This performance approaches the critical NT-proBNP concentration threshold often used by physicians for risk stratification purposes: $\sim 0.116 \mathrm{nM}$.
\end{abstract}

\section{Graphical Abstract}

\footnotetext{
Corresponding AuthorRichard M. Crooks - Department of Chemistry, The University of Texas at Austin, Austin, Texas 78712-1224, United States; crooks@cm.utexas.edu.

The authors declare no competing financial interest.

Supporting Information

The Supporting Information is available free of charge at https://pubs.acs.org/doi/10.1021/acssensors.0c00167.

Description of the electrochemical platform used for Au pre-electrodeposition and for determining the amount of Ag charge obtained from the metalloimmunoassay for NT-proBNP; scanning electron microscopy micrographs of the carbon paste working electrode before and after Au electrodeposition; ELISA results for the half indirect ELISA with hCG and CNP, performed with anti-hCG and anti-CNP Abs; Protocols for the preparation of the AgNP-HBCL-Ab conjugate, the physisorbed AgNP-Ab conjugate, and the M $\mu \mathrm{B}-$ Ab conjugate $(\mathrm{PDF})$
} 


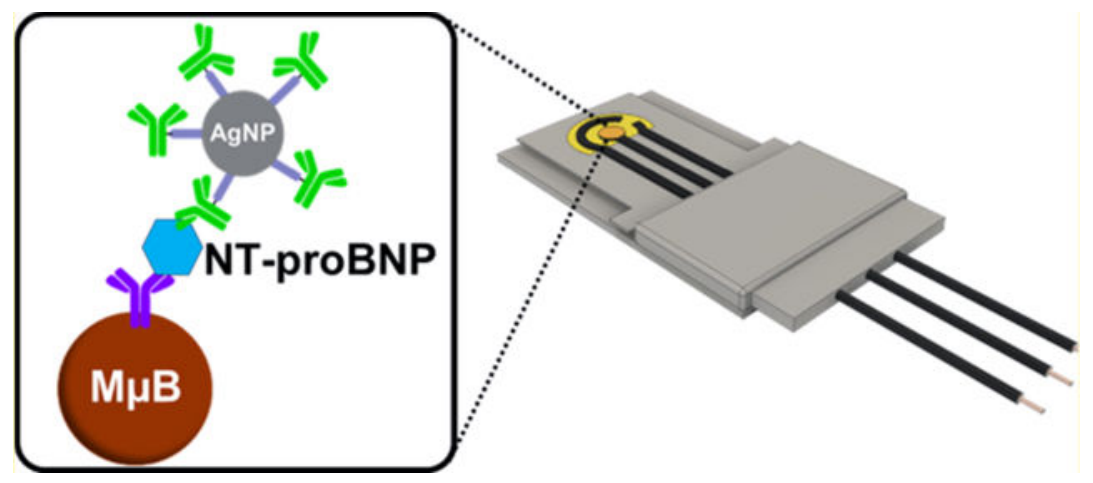

\section{Keywords}

$\mathrm{N}$-terminal prohormone brain natriuretic peptide; galvanic exchange; paper-based sensor; heterobifunctional cross-linker; metalloimmunoassay; heart failure

Here, we report on the detection of the cardiac biomarker, N-terminal prohormone brain natriuretic peptide (NT-proBNP), using a metalloimmunoassay adapted to a paper based electrochemical sensor. There are four important outcomes of this study. First, the use of a heterobifunctional cross-linker (HBCL), instead of the more common physisorption technique, for the bioconjugation of monoclonal immunoglobulin $\mathrm{G}$ antibodies (Abs) to silver nanoparticle (AgNP) labels improves the limit of detection and reproducibility of the assay. Second, the assay is selective in which there is no cross-reactivity with other cardiac natriuretic peptides, such as brain, atrial, and C-type natriuretic peptides (BNP, ANP, and CNP, respectively). ${ }^{1-3}$ Third, detection of NT-proBNP is not impacted by matrix effects ${ }^{4,5}$ in which the sandwich assay forms in undiluted human serum prior to analysis. Finally, and most important, the assay is able to detect NT-proBNP at concentrations between 0.58 and $2.33 \mathrm{nM}$ with an overall relative standard deviation of $<15 \%$. These findings represent a notable contribution to current efforts aimed at detecting NT-proBNP using a state-of-the-art system that is evolving toward home-use applications. ${ }^{6-9}$

NT-proBNP is a peptide that is secreted by ventricular cardiomyocytes that are stretched as a consequence of cardiac volume overload. ${ }^{10,11}$ Stretching of these heart muscle cells results in secretion of proBNP, which is enzymatically cleaved into BNP and NT-proBNP before being released into the bloodstream. ${ }^{11,12}$ The primary function of natriuretic peptides, such as BNP, ANP, and CNP, is to lower blood pressure by increasing natriuresis and diuresis (reducing excess salt and water retention), inhibit the production and action of vasoconstrictor peptides, and promote vascular relaxation. ${ }^{13}$ The overall effect of this cascade of events is to reduce cardiac output and central venous pressure.

Because they both originate from proBNP, BNP and NT-proBNP are initially present in equal concentrations in the body. The biological function of NT-proBNP is unknown, but for a number of reasons, it is used as a proxy for BNP in clinical settings to track the progression and severity of heart failure (HF). One of those reasons is that the circulation half-life of NT-proBNP in the body is six times longer than BNP (120 vs 20 min, respectively), making it a more desirable biomarker for HF. ${ }^{14}$ 
The critical NT-proBNP concentration threshold used by physicians for risk stratification purposes is $1000 \mathrm{pg} / \mathrm{mL}(116 \mathrm{pM}) .{ }^{15-18}$ This threshold allows physicians to identify HF patients as being at a high or low risk of hospitalization or mortality. It should be noted, however, that serum natriuretic peptide concentration values can vary greatly depending on comorbidities, race, disease severity, and the age of the patient. ${ }^{18-23}$ Because of this variability, it would be desirable for HF patients to be able to monitor their HF status at home because this could reduce the likelihood of decompensation and hospitalization. ${ }^{24-26}$ This is the motivation for the study presented here.

There are numerous analytical methods for detecting NT-proBNP, such as enzyme-linked immunosorbent assays (ELISA), ${ }^{27,28}$ immunofluorescence, ${ }^{29,30}$ and electrochemiluminescence (ECL). ${ }^{31-34}$ These methods typically require some type of immunological or aptameric ${ }^{35,36}$ technique to capture the peptide and also a signal amplification mechanism. ${ }^{37}$ For example, in 2017, Shi et al. developed a sandwich-type (immunoassay) ECL sensor for detecting clinical levels of NT-proBNP, in which the concentration of NT-proBNP in diluted human serum was correlated to the ECL quenching efficiency. ${ }^{33}$ In another example, an immunochromatographic assay consisting of monoclonal Abs labeled with a genetically engineered fluorescent protein was used to capture NT-proBNP on nitrocellulose paper, and then the assay was quantified fluorometrically. ${ }^{30}$ While these methods provide low limits of detection, they are not appropriate for home-use.

Our group previously reported on electrochemical detection of NT-proBNP using a metalloimmunoassay consisting of a capture $\mathrm{Ab}$ conjugated to a magnetic microbead $(\mathrm{M} \mu \mathrm{B})$ and a AgNP-labeled detection Ab. ${ }^{38}$ As shown in Scheme 1, the detection process, which has its roots in a method reported by Limoges and coworkers, ${ }^{39}$ proceeds as follows. First, the peptide is captured by the $\mathrm{Ab}$ pair in solution, and then the $\mathrm{M} \mu \mathrm{B}$ is brought to the electrode surface by a magnetic force for detection (Scheme 1a). In this case, and in our previous reports, ${ }^{40-42}$ the detection $\mathrm{Ab}$ is physisorbed to a AgNP label. Second, a process known as galvanic exchange (GE) is used to detect the AgNPs electrochemically. ${ }^{43,44} \mathrm{GE}$ takes advantage of a difference in the standard potentials of two metals such that they undergo a redox process. In our detection system (Scheme 1b), the metals are $\mathrm{Au}$ and $\mathrm{Ag}$ ( $E$ ${ }^{\circ}=1.52$ and $0.79 \mathrm{~V}$, respectively). ${ }^{45}$ The more noble $\mathrm{Au}^{0}$ is pre-electrodeposited on an electrode and then is electrochemically oxidized to $\mathrm{Au}^{3+}$, which subsequently diffuses to the AgNPs and then spontaneously exchanges with the less noble, zerovalent AgNP labels. This results in oxidation of the $\mathrm{AgNPs}$ to $\mathrm{Ag}^{+}$, which, in a third step, is subsequently electrodeposited onto the working electrode (Scheme 1c). Finally, anodic stripping voltammetry (ASV) is used to quantify the amount of Ag on the electrode surface. The resulting charge is directly related to the amount of target originally present in the sample.

The predominant means for immobilizing Abs on metal nanoparticles is physisorption. $39,46-50$ In this context, physisorption relies primarily on interactions between the surface of a metal, and thiol and amine residues which are present on Abs. ${ }^{51,52}$ While this bioconjugation method is quick and simple, the active orientation of the Abs on the nanoparticle surface is not well controlled unless the $\mathrm{Ab}$ is specifically engineered to bind in a particular way. ${ }^{53}$ Misorientation of the detection $\mathrm{Ab}$ can result in poor activity of the $\mathrm{Ab}$ in 
a metalloimmunoassay. ${ }^{54}$ An additional disadvantage of physisorption is that there is a likelihood that other biomolecules present in real biological matrixes will effectively compete for the metal nanoparticle surface, thereby dislodging the detection Abs. ${ }^{4,5,51,55}$ For these reasons, we sought to control the orientation of the Abs on the AgNP surface with a hydrazide and dithiolane-containing HBCL, which has previously been reported by our group $^{56}$ to have a positive effect on the capture efficiency of Abs on the surface of AgNPs by targeting the fragment crystallizable $(\mathrm{Fc})$ region. ${ }^{57}$

The primary goal of the present article is to report a bioassay that can be integrated into an electrochemical detection workflow on a paper-based, point-of-need device. Accordingly, we report on a metalloimmunoassay for NT-proBNP using a HBCL to bioconjugate AgNPs to the detection $\mathrm{Ab}$ rather than the more common physisorption technique. This makes it possible to detect NT-proBNP near the risk stratification threshold in buffered solution. Additionally, the assay is selective for NT-proBNP compared to other cardiac natriuretic peptides, and it resists matrix effects associated with human serum.

\section{EXPERIMENTAL SECTION}

\section{Chemicals and Materials.}

All solutions were prepared using deionized (DI) water (>18.0 M $\Omega \mathrm{cm}$, Milli-Q Gradient System, Millipore, Burlington, MA). Phosphate buffered saline (PBS) pH 7.4 (P3813), casein, superblock blocking buffer containing PBS (SBB) (cat. no. 37515), siliconized lowretention microcentrifuge tubes, $\mathrm{H}_{2} \mathrm{SO}_{4}, \mathrm{HAuCl}_{4}, \mathrm{KNO}_{3}$, Whatman grade 1 chromatography paper $(180 \mu \mathrm{m}$ thick, $20 \mathrm{~cm} \times 20 \mathrm{~cm}$ sheets, linear flow rate of water $=0.43 \mathrm{~cm} / \mathrm{min})$, and Costar 3590 high-binding microtiter plates were purchased from Fisher Scientific (Pittsburgh, PA). A horseradish peroxidase (HRP) conjugate kit (cat. no. LNK002P) was purchased from Bio-Rad (Richmond, CA).

All PBS concentrations were $1 \times$. The $5 \mathrm{kDa}$ mPEG-SH was obtained from Nanocs (New York, NY). 1-Step Ultra TMB-ELISA substrate solution (34028) and sodium meta-periodate $\left(\mathrm{NaIO}_{4}\right)$ were obtained from Thermo Scientific (Grand Island, NY). Citrate-capped AgNPs (nominal $20 \mathrm{~nm}$ diameter) were purchased from nano Composix (San Diego, CA). NTproBNP, monoclonal immunoglobulin G anti-NT-proBNP 13G12 detection Ab, biotinylated monoclonal immunoglobulin G anti-NT-proBNP 15C4 capture Ab (15C4-biotin), and nonbiotinylated monoclonal immunoglobulin G anti-NT-proBNP 15C4 capture Ab were obtained from HyTest (Turku, Finland). Polyclonal antimouse immunoglobulin G HRP labeled secondary antibody (SAb) and proBNP were obtained from Abcam (Cambridge, UK). ANP, CNP, BNP, and polyoxyethylene (20) sorbitan monolaurate (Tween-20) were purchased from Sigma Aldrich (St. Louis, MO). Human chorionic gonadotropin (hCG) was purchased from Fitzgerald (Acton, MA). Streptavidin-coated $\mathrm{M} \mu \mathrm{Bs}$ having a diameter of 1.0 $\mu \mathrm{m}$ (cat. no. 65601) were obtained from Life Technologies (Grand Island, NY).

Amicon ultra $0.5 \mathrm{~mL}$ centrifugal filters $(10 \mathrm{~K})$ and normal human serum were purchased from Millipore-Sigma (Taunton, MA). Conductive carbon paste (Cl-2042) was purchased from Engineered Conductive Materials (Delaware, $\mathrm{OH}$ ). Cylindrical neodymium magnets 
(1/16 in. $\times 1 / 2$ in., N48) were purchased from Apex Magnets (Petersburg, WV). All chemicals and reagents were used without further purification unless otherwise specified.

\section{Instrumentation.}

Absorbance measurements were obtained and path length corrected using a Synergy H4 Hybrid Multi-Mode Microplate Reader from BioTek (Winooshi, VT). A Sorvall Legend Micro 21R centrifuge from Thermo Scientific (Grand Island, NY) was used for washing and separation steps during bioconjugation. A tube revolver (cat. no. 88881001), also from Thermo Scientific, was used for incubation steps during the conjugation of Abs to $\mathrm{M} \mu \mathrm{Bs}$. A Mini Vortexer (945300) from VWR International (Radnor, PA) was used to briefly mix solutions while a BioShake iQ from Quantifoil Instruments GmbH (Jena, Germany) was used for incubation steps during bioconjugation. A magnetic bead separation block (cat. no. VP771HH-Rz) was purchased from V\&P Scientific (San Diego, CA) and was used for washing steps involving $\mathrm{M} \mu \mathrm{Bs}$.

\section{Electrode Fabrication.}

A slight modification of a previously published procedure was used to fabricate the electrodes. ${ }^{43}$ Specifically, they were fabricated by stencil-printing carbon paste onto waxpatterned sheets of chromatography paper that had been printed using a Xerox ColorQube 8570DN printer. Following printing, the wax was melted through the thickness of the paper by placing it in an oven at $120^{\circ} \mathrm{C}$ for $25.0 \mathrm{~s}$. Photopaper was glued to the back of the waxprinted chromatography paper to improve rigidity, and then it was cut into 12 rectangles ( 2.0 $\mathrm{cm} \times 5.0 \mathrm{~cm}$, each). A stencil for defining the $3.0 \mathrm{~mm}$-diameter disk-shaped working electrode, hook-shaped carbon quasi-reference electrode, and counter electrode was created using CorelDRAW (Ottawa, ON). The stencil was cut into a thin plastic sheet of transparency film using an Epilog laser engraving system (Zing 16). Finally, the stencil was placed over the paper (wax side up), the electrodes were printed through the stencil using the conductive carbon paste, and then they were left to dry in air for $14 \mathrm{~h}$ (Figure S1).

The working electrode was further modified by electrodepositing Au onto the carbon paste. This step was performed on-chip and was carried out by placing a $50.0 \mu \mathrm{L}$ droplet of a solution consisting of $6.0 \mathrm{mM} \mathrm{HAuCl}_{4}$ and $0.10 \mathrm{M} \mathrm{KNO}_{3}$ on the electrode region of the sensor. Because the region of the sensor incorporating the electrodes is hydrophilic relative to the rest of the paper assembly, the deposition solution was confined to just the electrode region, and hence, no additional electrochemical cell was required. Next, the potential of the working electrode was stepped from 0 to $-0.60 \mathrm{~V}$ (unless otherwise stated, all potentials are vs a carbon quasi-reference electrode, CQRE) for $2.0 \mathrm{~s} .{ }^{43}$ This process results in islands of $\mathrm{Au}$ (not a conformal coating) on the surface of the carbon (Figure S2). ${ }^{43}$ The electrode was then rinsed twice with DI water and dried with a Kimwipe (Figure S1).

\section{Electrochemical Detection.}

All electrochemical measurements were performed using a CH Instruments model 760B electrochemical workstation (Austin, TX). A previously published electrochemical protocol was used to determine the charge resulting from the process illustrated in Scheme $1 .^{43}$ Briefly, to initiate GE, the potential of the working electrode was stepped from 0 to $0.80 \mathrm{~V}$ 
for $12.0 \mathrm{~s}$ to oxidize $\mathrm{Au}^{0}$ to $\mathrm{Au}^{3+}$. Next, the potential was stepped from 0 to $-0.70 \mathrm{~V}$ for 50.0 $\mathrm{s}$ to reduce $\mathrm{Ag}^{+}$to $\mathrm{Ag}^{0}$ onto the electrode. These two steps were carried out twice, and then the potential was swept two times from -0.70 to $0.20 \mathrm{~V}$ at a scan rate of $50.0 \mathrm{mV} / \mathrm{s}$ to oxidize $\mathrm{Ag}^{0}$. The charge resulting from the last ASV scan was obtained by integration and represents the output signal of the sensor. ${ }^{43,44}$ All electrochemical measurements were performed in a PBS solution.

\section{Assessing Ab Cross-Reactivity.}

The cross-reactivity of the $13 \mathrm{G} 12$ and $15 \mathrm{C} 4$ Abs was determined using an indirect, halfsandwich ELISA, and a mixed antigen, sandwich ELISA. The 13G12-HRP Ab was prepared using a kit and protocol provided by the manufacturer. ${ }^{58}$ Unless stated otherwise, all incubation steps were performed for $30 \mathrm{~min}$ at $600 \mathrm{rpm}$ at room temperature (RT) (22 \pm 3 ${ }^{\circ} \mathrm{C}$ ) and were followed by three washing steps with PBS. Briefly, $100 \mu \mathrm{L}$ of $58.2 \mathrm{nM} \mathrm{NT}$ proBNP, proBNP, BNP, ANP, CNP, or hCG in PBS was incubated for $14 \mathrm{~h}$ at $4{ }^{\circ} \mathrm{C}$ without shaking in a high-binding microtiter plate. Second, the wells were blocked by adding $400 \mu \mathrm{L}$ of $2 \%$ (w/v) casein solution in PBS for 30 min without shaking. Third, $100 \mu \mathrm{L}$ of $6.7 \mu \mathrm{M}$ of $13 \mathrm{G} 12 \mathrm{Ab}$ was added to each well and incubated. The same process was carried out with the $15 \mathrm{C} 4 \mathrm{Ab}$. Fourth, $100 \mu \mathrm{L}$ of $6.7 \mu \mathrm{M}$ the SAb was added to each well and incubated. Finally, $100 \mu \mathrm{L}$ of the 1-Step Ultra TMB-ELISA substrate solution was added, and $50.0 \mu \mathrm{L}$ of $2 \mathrm{M}$ $\mathrm{H}_{2} \mathrm{SO}_{4}$ was used to quench the reaction after it reached the desired color intensity ( $\sim 3 \mathrm{~min}$ ), and then the absorbance was measured at $450 \mathrm{~nm}$. The degree of cross-reactivity was determined quantitatively. That is, if the Abs were cross-reactive with the different targets on the plate, a color change would be observed. Positive controls were also performed to ensure that all the assay components were functioning properly. Specifically, hCG and CNP were detected using an anti-hCG or anti-CNP Ab, respectively (Figure S3).

A complementary cross-reactivity experiment, similar to that described in the previous paragraph, was also performed. In this case, a mixed antigen, sandwich ELISA for NTproBNP was prepared in the presence of all the potentially cross-reactive species. Specifically, this experiment was carried out by first immobilizing the anti-NT-proBNP capture $\mathrm{Ab}$ by adding $100 \mu \mathrm{L}$ of $6.7 \mu \mathrm{M}$ of the $15 \mathrm{C} 4 \mathrm{Ab}$ to the wells of a microtiter plate. Next, a $100 \mu \mathrm{L}$ mixture containing $58.2 \mathrm{nM}$ of each of the following was introduced: NTproBNP, BNP, CNP, and ANP. Next, $100 \mu \mathrm{L}$ of $6.7 \mu \mathrm{M}$ 13G12-HRP detection Ab was added to each well. Finally, $100 \mu \mathrm{L}$ of the 1-Step Ultra TMB-ELISA substrate solution was added, and $50.0 \mu \mathrm{L}$ of $2 \mathrm{M} \mathrm{H}_{2} \mathrm{SO}_{4}$ was used to quench the reaction after it reached the desired color intensity ( $\sim 3 \mathrm{~min}$ ). The blank for this experiment was prepared following the same procedure; however, SBB was added to the wells in place of the antigen mixture.

An advantage of the Abs used for this assay is that they target amino acids at the ends of the NT-proBNP peptide. This is important, because post-translational modifications of peptides, such as glycosylation, can hinder the ability of Abs to recognize a specific target. Indeed, endogenous NT-proBNP is known to have several locations on its amino acid sequence where glycosylation occurs. These regions are amino acids located in the middle of the peptide: amino acids $28-60.59$ These regions are avoided by the Ab pair used in this study. 3,60 


\section{Preparing Assay Components.}

The 13G12 Ab was conjugated to the AgNPs using a previously published protocol, and a more detailed version can be found in the Supporting Information. ${ }^{47,48}$ Briefly, the $13 \mathrm{G} 12$ $\mathrm{Ab}$ was modified by bioconjugating it to a HBCL. The modified Ab was then added to 500 $\mu \mathrm{L}$ of AgNPs $\left(4.9 \times 10^{11} \mathrm{AgNPs} / \mathrm{mL}\right)$ and incubated for $1 \mathrm{~h}$, followed by back-filling with $\mathrm{mPEG}-\mathrm{SH}$ for $20 \mathrm{~min}$ at $600 \mathrm{rpm}$ at RT. Excess conjugation reagents were then removed by centrifugation for $30 \mathrm{~min}$ at $16,600 \mathrm{~g}$ at $4{ }^{\circ} \mathrm{C}$. The formed conjugate was washed three times by centrifugation and then resuspended in $500 \mu \mathrm{L}$ of SBB. Henceforth, this will be referred to as the AgNP-HBCL-Ab conjugate. The protocol for preparing the physisorbed conjugate (denoted as $\mathrm{AgNP}-\mathrm{Ab}$ ), used for comparison, is provided in the Supporting Information.

The 15C4-biotin $\mathrm{Ab}$ was conjugated to streptavidin-coated $\mathrm{M} \mu \mathrm{Bs}$ using the protocol provided by the manufacturer. ${ }^{61}$ In short, $50.0 \mu \mathrm{L}$ of $\mathrm{M} \mu \mathrm{Bs}\left(\sim 7-10 \times 10^{9} \mathrm{M} \mu \mathrm{Bs} / \mathrm{mL}\right)$ was added to a SBB-blocked tube and washed by magnetic separation four times with PBS. Next, 30.0 $\mu \mathrm{L}$ of $4.6 \mu \mathrm{M}$ 15C4-biotin Ab and $20.0 \mu \mathrm{L}$ of PBS were added to the tube and incubated for $30 \mathrm{~min}$ at $40 \mathrm{rpm}$ at RT, using the tube revolver. Finally, the conjugated $\mathrm{M} \mu \mathrm{Bs}$ were washed by magnetic separation five times with SBB and resuspended to a final volume of50.0 $\mu \mathrm{L}$. Henceforth, this will be referred to as the $\mathrm{M} \mu \mathrm{B}-\mathrm{Ab}$ conjugate. A more detailed protocol is provided in the Supporting Information.

\section{Step-Wise Formation of the NT-proBNP Metalloimmunoassay.}

Once all the assay components were prepared, they were used in the full metalloimmunoassay for NT-proBNP. This assay was formed in SBB-blocked wells of a microtiter plate as follows. First, $2.0 \mu \mathrm{L}$ of the $\mathrm{M} \mu \mathrm{B}-\mathrm{Ab}$ conjugate was placed in each well along with $100 \mu \mathrm{L}$ of a known concentration of NT-proBNP in SBB. These components were incubated for $30 \mathrm{~min}$ at $1000 \mathrm{rpm}$ at RT. Next, the partially formed assay was washed to remove unbound peptide. Washing was performed by magnetic separation wherein the $\mathrm{M} \mu \mathrm{Bs}$ were collected at the bottom of the wells, the supernatant was removed, and the halfformed conjugate was resuspended in 1\% (v/v) Tween-20 and PBS solution. This washing step was performed three times. Next, $20.0 \mu \mathrm{L}$ of the AgNP-HBCL-Ab conjugate and 80.0 $\mu \mathrm{L}$ of SBB were added. This mixture was incubated using the procedure stated in the previous section and then washed by magnetic separation. The fully formed assay was resuspended in a final volume of $50.0 \mu \mathrm{L}$ of PBS and then transferred to the paper-based electrode. The $\mathrm{M} \mu \mathrm{Bs}$ were focused onto the working electrode ( 30.0 s) by the magnet (Figure S1), and the electrochemical analysis was performed as discussed earlier. For experiments involving assays formed in undiluted human serum, the same protocol was followed, except the NT-proBNP samples, and the assay components were diluted into serum rather than SBB.

\section{RESULTS AND DISCUSSION Determining Ab Cross-Reactivity.}

One of the most important aspects of any bioassay is its specificity. That is, the degree to which the assay can distinguish the target molecule from all other possible components of a biological sample. In our case, other natriuretic peptides can be considered good model 
cross-reactants for the NT-proBNP-targeting Abs used in this study. Accordingly, we carried out two sets of cross reactivity studies using NT-proBNP, proBNP, BNP, ANP, CNP, and hCG. The first set used an indirect, half-sandwich ELISA to specifically check for individual antigen cross reactivity for each $\mathrm{Ab}$ of the assay, while the second set used a sandwich ELISA to perform a mixed-antigen cross-reactivity experiment (described in the Experimental Section). Briefly, for the indirect, half-sandwich ELISA, the model cross reactants were immobilized in different wells of a microtiter plate, and then either the unmodified 13G12 detection $\mathrm{Ab}$ or the $15 \mathrm{C} 4$ capture $\mathrm{Ab}$ was added to the wells, followed by a SAb. In the case of the mixed-antigen cross-reactivity experiment, the $15 \mathrm{C} 4$ capture $\mathrm{Ab}$ was immobilized on the plate, followed by the addition of the antigen mixture (including NT-proBNP) to the wells of the plate, and then a 13G12-HRP signaling Ab. The degree of reactivity was determined by UV-vis spectroscopy for both experiments.

Figures 1a, b shows the results of the foregoing experiments obtained using the $13 \mathrm{G} 12$ detection $\mathrm{Ab}$ and the $15 \mathrm{C} 4$ capture $\mathrm{Ab}$, respectively. The histograms indicate that these two Abs are not cross-reactive with the other natriuretic peptides tested or with hCG. A positive control experiment was also performed (Figure S3), which further validates this conclusion.

Figure 1c displays the results for the mixed-antigen cross reactivity experiment. These results show that even in the presence of multiple antigens that are related to NT-proBNP, NT-proBNP is captured to the same degree as when the potential interferants are omitted. It is important to note that because NT-proBNP originates from proBNP, the Ab pair also recognizes proBNP (which was omitted in this mixed antigen experiment). This has little impact on the bioassay, however, because most commercial assays capture both NT-proBNP and proBNP, and the latter is almost ten times lower in concentration than NT-proBNP in HF patient samples. $^{2}$

\section{Comparing Physisorbed and HBCL-Modified Conjugates.}

After ensuring that the Ab pair used for the analysis is not cross-reactive with the other tested natriuretic peptides, two different bioconjugation routes were explored to determine the best technique for immobilizing the detection $\mathrm{Ab}$ on the AgNP label: physisorption and HBCL modification. These experiments were carried out by preparing both the physisorbed $\mathrm{AgNP}-\mathrm{Ab}$ and the AgNP-HBCL-Ab conjugates, as described in the Experimental Section, and then using them to electrochemically detect a single concentration of NT-proBNP in the full metalloimmunoassay (detection of multiple concentrations is discussed in the next section). Specifically, the metalloimmunoassay was formed with $100.0 \mu \mathrm{L}$ of $0.58 \mathrm{nM} \mathrm{NT}$ proBNP and $2.0 \mu \mathrm{L}$ of the $\mathrm{M} \mu \mathrm{B}-\mathrm{Ab}$ conjugate. The detection $\mathrm{Ab}$, which was in excess, was either physisorbed to the AgNP label (AgNP-Ab conjugate) or covalently attached using the HBCL (AgNP-HBCL-Ab conjugate). After assay formation, the electrochemical protocol was executed.

Figure 2 is a histogram comparing the Ag charge obtained using the two different conjugation methods. These data represent five independently prepared assays analyzed on independently prepared paper electrodes. The magnitude of the signal arising from the AgNP-HBCL-Ab conjugate is 27-fold higher than that of the AgNP-Ab (physisorbed) conjugate. Specifically, the charge arising from the AgNP-HBCL-Ab conjugate was $1.90 \pm$ 
0.18 versus $0.07 \pm 0.01 \mu \mathrm{C}$ for the conjugate formed by physisorption. As mentioned earlier, there is a direct correlation between the measured charge and the amount of peptide captured in the assay, which means that the HBCL leads to an increased target peptide capture and a lower limit of detection.

Physisorption is widely used in the literature as a simple means for immobilizing Abs on NP surfaces; however, this technique has limitations. As noted previously, one of these is that there is usually (but not always) ${ }^{53}$ limited control over the orientation of the Ab on the surface of the particle. This is a consequence of the fact that conjugation by physisorption does not target a specific region of the Ab. ${ }^{51}$ The advantage of the HBCL, and specifically the hydrazone chemistry used in this study, is that it exclusively targets the polysaccharide groups residing in the $\mathrm{Fc}$ region of the Ab. This ensures that the antigen-binding fragment (Fab) regions of the $\mathrm{Ab}$ are completely accessible to the target molecule. ${ }^{56,57}$ Indeed, the results in Figure 2 suggest that the 13G12 detection Ab is more effectively oriented for capturing NT-proBNP. Additionally, we have previously shown that the Ab is also more strongly attached to the nanoparticle when the HBCL is used instead of physisorption. ${ }^{56}$ Accordingly, the AgNP-HBCL-Ab conjugate was selected for subsequent experiments.

\section{Detecting Multiple Concentrations of NT-proBNP.}

After determining that the HBCL-modified detection Ab performs better than the physisorbed AgNP-Ab conjugate, the latter was used for preparing a dose-response curve. The assay was prepared in SBB using a step-wise procedure as described in the Experimental Section. Briefly, $2.0 \mu \mathrm{L}$ of the $\mathrm{M} \mu \mathrm{B}-\mathrm{Ab}$ conjugates was added to the wells of a preblocked microtiter plate, and then $100 \mu \mathrm{L}$ of varying concentrations of NT-proBNP was added. Following incubation and washing, an excess of the AgNP-HBCL-Ab conjugate was added to the wells. Once the assay was fully formed, the entire content of the well was transferred to the paper electrode, and the electrochemical protocol was carried out in PBS.

Figure 3 shows the results of this experiment. The voltammograms in Figure 3a indicate that the AgNP oxidation current increases as a function of the concentration of NT-proBNP used to form the bioassay. The charges under the voltammograms were obtained by integration, and the results for five independent experiments per concentration are plotted in Figure $3 \mathrm{~b}$. These data demonstrate that the charge increases linearly from 0.58 to $2.33 \mathrm{nM}$ of NTproBNP and then it begins to saturate (the data point for $12.0 \mathrm{nM}$ is not shown in Figure $3 \mathrm{~b}$, but it is about the same as the point for $7.0 \mathrm{nM}$ ). Note that concentrations below $0.58 \mathrm{nM}$ could not be differentiated from the blank and are thus not shown in Figure 3. An additional important feature of Figure $3 \mathrm{~b}$ is that the overall relative standard deviation of this assay is $<15 \%$.

To put the linear range of the bioassay into perspective, the critical concentration used by physicians to identify HF patients who are at risk of poor outcomes is $1000 \mathrm{pg} / \mathrm{mL}(116$ $\mathrm{pM}) .{ }^{15,16}$ Accordingly, the results in Figure $3 \mathrm{~b}$ indicate that the performance of the bioassay is approaching the risk stratification threshold. Clearly, additional work is required to further reduce the limit of detection, but to the best of our knowledge, the value, we have achieved thus far, is the lowest reported for detection of NT-proBNP using a simple, paper based device. $^{38}$ 


\section{Forming the Metalloimmunoassay in Undiluted Serum.}

The primary goal of the present article is to report on a bioassay that can be easily integrated into a point-of-need device. In part, this means an assay having the ability to capture NTproBNP from a serum matrix. Accordingly, the full metalloimmunoassay for NT-proBNP was prepared exactly as described in the previous section, but in this case, one set of replicates was prepared in SBB and another in undiluted human serum, both spiked with $0.58 \mathrm{nM}$ NT-proBNP. The assays were formed in their respective matrixes, washed with $1 \%$ $(\mathrm{v} / \mathrm{v})$ Tween-20 and PBS, resuspended in PBS, and transferred to the paper-based electrodes for electrochemical detection.

Figure 4 displays representative ASVs for the assays formed in both SBB and human serum. The blank for this experiment was the assay formed in serum with no NT-proBNP present. The Ag charge obtained from this experiment was $0.60 \pm 0.10 \mu \mathrm{C}$, regardless of whether the assay was formed in SBB or undiluted human serum. This means that the serum matrix has no detectable adverse effects on formation of the assay. Note, however, that there is some batch-to-batch variation in the preparation of the assay conjugate solutions. For example, different batches were used to obtain the data shown in Figures 4 and $3 \mathrm{~b}$, and therefore, the charges corresponding to $0.58 \mathrm{nM}$ of NT-proBNP are different $(0.60 \pm 0.10$ vs $1.90 \pm 0.18$ $\mu \mathrm{C}$, respectively) for these two experiments.

\section{SUMMARY AND CONCLUSIONS}

To summarize, the goal of this study was to describe a bioassay that can be integrated into an electrochemical detection workflow on a paper-based, point-of-need device for the detection of NT-proBNP. The detection limit of $0.58 \mathrm{nM}$ of NT-proBNP is promising at this stage for such a simple immunological sensor. Indeed, we found that a 27 -fold increase in detection efficiency is observed by just improving the linking chemistry between the detection $\mathrm{Ab}$ and the AgNP label. We attributed this result to the controlled orientation of the detection $\mathrm{Ab}$ on the surface of the AgNP label. ${ }^{56,57}$ This advance made it possible to detect NT-proBNP near the risk stratification threshold with a relative standard deviation of $<15 \%$. Additionally, using both an indirect and a full-capture ELISA, we showed that the Ab pair selected for this bioassay was not cross-reactive with other cardiac natriuretic peptides. Finally, the bioassay could be formed in undiluted human serum with no change in signal (compared to buffer).

The detection method reported in this article provides a simple means for detecting an important HF marker that may be relevant in the evolving at-home, personal medicine environment. $6,27,36,62$ There is, however, much more work to do. Specifically, it is necessary to further lower the limit of detection, eliminate all off-chip reagents and manipulations, and test the device using human blood samples. It should be possible to lower the limit of detection if reagent ratios are further optimized, and if larger AgNPs are used to increase the Ag signal at the lower antigen concentrations. All of these tasks are underway in our lab, and the results will be reported in due course.

\section{Supplementary Material}

Refer to Web version on PubMed Central for supplementary material. 


\section{ACKNOWLEDGMENTS}

Research reported in this publication was supported by the National Heart, Lung, and Blood Institute of the National Institutes of Health under Award R01HL137601. The content is solely the responsibility of the authors and does not necessarily represent the official views of the National Institutes of Health. We thank the Robert A. Welch Foundation (grant F-0032) for sustained support of our research. We also thank Molly Kogan for assistance with electrode imaging.

\section{REFERENCES}

(1). Saenger AK; Rodriguez-Fraga O; Ler R; Ordonez-Llanos J; Jaffe AS; Goetze JP; Apple FS Specificity of B-Type Natriuretic Peptide Assays: Cross-Reactivity with Different BNP, NTProBNP, and ProBNP Peptides. Clin. Chem 2017, 63, 351-358. [PubMed: 28062628]

(2). Seferian KR; Tamm NN; Semenov AG; Mukharyamova KS; Tolstaya AA; Koshkina EV; Kara AN; Krasnoselsky MI; Apple FS; Esakova TV; et al. The Brain Natriuretic Peptide (BNP) Precursor Is the Major Immunoreactive Form of BNP in Patients with Heart Failure. Clin. Chem 2007, 53, 866-873. [PubMed: 17384012]

(3). Seferian KR; Tamm NN; Semenov AG; Tolstaya AA; Koshkina EV; Krasnoselsky MI; Postnikov AB; Serebryanaya DV; Apple FS; Murakami MM; et al. Immunodetection of Glycosylated NTProBNP Circulating in Human Blood. Clin. Chem 2008, 54, 866-873. [PubMed: 18339697]

(4). Treuel L; Brandholt S; Maffre P; Wiegele S; Shang L; Nienhaus GU Impact of Protein Modification on the Protein Corona on Nanoparticles and Nanoparticle-Cell Interactions. ACS Nano 2014, 8, 503-513. [PubMed: 24377255]

(5). Ruiz G; Ryan N; Rutschke K; Awotunde O; Driskell JD Antibodies Irreversibly Adsorb to Gold Nanoparticles and Resist Displacement by Common Blood Proteins. Langmuir 2019, 35, 1060110609. [PubMed: 31335148]

(6). Sonawane MD; Nimse SB; Song K-S; Kim T Multiplex Detection of Cardiac Biomarkers. Anal. Methods 2017, 9, 3773-3776.

(7). Lutz S; Lopez-Calle E; Espindola P; Boehm C; Brueckner T; Spinke J; Marcinowski M; Keller T; Tgetgel A; Herbert N; et al. A Fully Integrated Microfluidic Platform for Highly Sensitive Analysis of Immunochemical Parameters. Analyst 2017, 142, 4206-4214. [PubMed: 29043325]

(8). Li Z; Ausri IR; Zilberman Y; Tang X Towards Label-Free, Wash-Free and Quantitative B-Type Natriuretic Peptide Detection for Heart Failure Diagnosis. Nanoscale 2019, 11, 18347-18357. [PubMed: 31573591]

(9). Liang W; Li Y; Zhang B; Zhang Z; Chen A; Qi D; Yi W; Hu C A Novel Microfluidic Immunoassay System Based on Electrochemical Immunosensors: An Application for the Detection of NT-ProBNP in Whole Blood. Biosens. Bioelectron 2012, 31, 480-485. [PubMed: 22169814]

(10). Roger VL Epidemiology of Heart Failure. Circ. Res 2013, 113, 646-659. [PubMed: 23989710]

(11). Kuhn M A big-hearted molecule. Nature 2015, 519, 416-417. [PubMed: 25799985]

(12). Semenov AG; Tamm NN; Seferian KR; Postnikov AB; Karpova NS; Serebryanaya DV; Koshkina EV; Krasnoselsky MI; Katrukha AG Processing of Pro-B-Type Natriuretic Peptide: Furin and Corin as Candidate Convertases. Clin. Chem 2010, 56, 1166-1176. [PubMed: 20489134]

(13). Levin ER; Gardner DG; Samson WK Natriuretic Peptides.N. Engl. J. Med 1998, 339, 321-328.

(14). Kim H-N; Januzzi JL Natriuretic Peptide Testing in Heart Failure. Circulation 2011, 123, 20152019. [PubMed: 21555724]

(15). Zile MR; Claggett BL; Prescott MF; McMurray JJV; Packer M; Rouleau JL; Swedberg K; Desai AS; Gong J; Shi VC; et al. Prognostic Implications of Changes in N-Terminal Pro-B Type Natriuretic Peptide in Patients With Heart Failure. J. Am. Coll. Cardiol 2016, 68, 2425-2436. [PubMed: 27908347]

(16). Michael Felker G; Ahmad T; Anstrom KJ; Adams KF; Cooper LS; Ezekowitz JA; Fiuzat M; Houston-Miller N; Januzzi JL; Leifer ES; et al. Rationale and Design of the Guide-It Study: Guiding Evidence Based Therapy Using Biomarker Intensified Treatment in Heart Failure. JACC Heart Fail 2014, 2, 458-465. 
(17). Masson S; Latini R; Anand IS; Vago T; Angelici L; Barlera S; Missov ED; Clerico A; Tognoni G; Cohn JN Direct Comparison of B-Type Natriuretic Peptide (BNP) and Amino Terminal ProBNP in a Large Population of Patients with Chronic and Symptomatic Heart Failure: The Valsartan Heart Failure (Val-HeFT) Data. Clin. Chem 2006, 52, 1528-1538. [PubMed: 16777915]

(18). Januzzi JL; Troughton R Are Serial BNP Measurements Useful in Heart Failure Management? Circulation 2013, 127, 500-508. [PubMed: 23357662]

(19). Yancy CW; Jessup M; Bozkurt B; Butler J; Casey DE; Drazner MH; Fonarow GC; Geraci SA; Horwich T; Januzzi JL; et al. 2013 ACCF/AHA Guideline for the Management of Heart Failure. J. Am. Coll. Cardiol 2013, 62, e147-e239. [PubMed: 23747642]

(20). Palazzuoli A; Gallotta M; Quatrini I; Nuti R Natriuretic Peptides (BNP and NT-ProBNP): Measurement and Relevance in Heart Failure. Vasc. Health Risk Manage 2010, 6, 411-418.

(21). Richards M; Troughton RW NT-ProBNP in Heart Failure: Therapy Decisions and Monitoring. Eur. J. Heart Failure 2004, 6, 351-354.

(22). McCullough PA; Kluger AY Interpreting the Wide Range of NT-ProBNP Concentrations in Clinical Decision Making. J. Am. Coll. Cardiol 2018, 71, 1201-1203. [PubMed: 29544602]

(23). Wu AHB; Smith A; Wieczorek S; Mather JF; Duncan B; White CM; McGill C; Katten D; Heller G Biological Variation for N-Terminal pro-and B-Type Natriuretic Peptides and Implications for Therapeutic Monitoring of Patients with Congestive Heart Failure. Am. J. Cardiol 2003, 92, 628631. [PubMed: 12943894]

(24). Don-Wauchope AC; McKelvie RS Evidence Based Application of BNP/NT-ProBNP Testing in Heart Failure. Clin. Biochem 2015, 48, 236-246. [PubMed: 25448029]

(25). Sud M; Yu B; Wijeysundera HC; Austin PC; Ko DT; Braga J; Cram P; Spertus JA; Domanski M; Lee DS Associations Between Short or Long Length of Stay and 30-Day Readmission and Mortality in Hospitalized Patients With Heart Failure. JACC Heart Fail. 2017, 5, 578-588. [PubMed: 28501521]

(26). Jourdain P; Jondeau G; Funck F; Gueffet P; Le Helloco A; Donal E; Aupetit JF; Aumont MC; Galinier M; Eicher JC; et al. Plasma Brain Natriuretic Peptide-Guided Therapy to Improve Outcome in Heart Failure. J. Am. Coll. Cardiol 2007, 49, 1733-1739. [PubMed: 17448376]

(27). Mohammed M-I; Desmulliez MPY Lab-on-a-Chip Based Immunosensor Principles and Technologies for the Detection of Cardiac Biomarkers: A Review. Lab Chip 2011, 11, 569-595. [PubMed: 21180774]

(28). Mainville CA; Clark GH; Esty KJ; Foster WM; Hanscom JL; Hebert KJ; Lyons HR Analytical validation of an immunoassay for the quantification of N-terminal pro-B-type natriuretic peptide in feline blood. J. Vet. Diagn. Invest 2015, 27, 414-421. [PubMed: 26077545]

(29). Song K-S; Nimse SB; Sonawane MD; Warkad SD; Kim T Ultra-Sensitive NT-ProBNP Quantification for Early Detection of Risk Factors Leading to Heart Failure. Sensors 2017, 17, 2116.

(30). Li H; Yin X; Sun D; Xia K; Kang C; Chu S; Zhang P; Wang H; Qiu Y Detection of NT-pro BNP Using Fluorescent Protein Modified by Streptavidin as a Label in Immunochromatographic Assay. Sens Biosensing Res 2016, 11, 1-7.

(31). Liu Y; Wang H; Xiong C; Chai Y; Yuan R An Ultrasensitive Electrochemiluminescence Immunosensor for NT-ProBNP Based on Self-Catalyzed Luminescence Emitter Coupled with PdCu@ carbon Nanohorn Hybrid. Biosens. Bioelectron 2017, 87, 779-785. [PubMed: 27649335]

(32). Zhang H; Han Z; Wang X; Li F; Cui H; Yang D; Bian Z Sensitive Immunosensor for N-Terminal pro-Brain Natriuretic Peptide Based on N-(Aminobutyl)-N-(Ethylisoluminol)-Functionalized Gold Nanodots/Multiwalled Carbon Nanotube Electrochemiluminescence Nanointerface. ACS Appl. Mater. Interfaces 2015, 7, 7599-7604. [PubMed: 25801201]

(33). Shi L; Li X; Zhu W; Wang Y; Du B; Cao W; Wei Q; Pang X Sandwich-Type Electrochemiluminescence Sensor for Detection of NT-proBNP by Using High Efficiency Quench Strategy of $\mathrm{Fe}_{3} \mathrm{O}_{4} @$ PDA toward $\mathrm{Ru}(\text { bpy })_{3}{ }^{2+}$ Coordinated with Silver Oxalate. ACS Sens. 2017, 2, 1774-1778. [PubMed: 29227092]

(34). Prontera C; Emdin M; Zucchelli GC; Ripoli A; Passino C; Clerico A Analytical Performance and Diagnostic Accuracy of a Fully-Automated Electrochemiluminescent Assay for the N-Terminal Fragment of the pro-Peptide of Brain Natriuretic Peptide in Patients with Cardiomyopathy: 
Comparison with Immunoradiometric Assay Methods. Clin. Chem. Lab. Med 2004, 42, 37-44. [PubMed: 15061378]

(35). Sinha A; Sinhamahapatra A; Gopinnathan P; Chung Y-D; Shiesh S-C Simultaneous Detection of Multiple NT-ProBNP Clinical Samples Utilizing an Aptamer-Based Sandwich Assay on an Integrated Microfluidic System. Lab Chip 2019, 19, 1676-1685. [PubMed: 30942226]

(36). Sinha A; Gopinathan P; Chung Y-D; Shiesh S-C; Lee G-B Simultaneous Detection of Multiple NT-ProBNP Clinical Samples Utilizing an Aptamer-Based Sandwich Assay on an Integrated Microfluidic System. Lab Chip 2019, 19, 1676-1685. [PubMed: 30942226]

(37). Labib M; Sargent EH; Kelley SO Electrochemical Methods for the Analysis of Clinically Relevant Biomolecules. Chem. Rev 2016, 116, 9001-9090. [PubMed: 27428515]

(38). DeGregory PR; Tapia J; Wong T; Villa J; Richards I; Crooks RM Managing Heart Failure at Home With Point-of-Care Diagnostics. IEEE J. Transl. Eng. Health Med 2017, 5, 1-6.

(39). Dequaire M; Degrand C; Limoges B An Electrochemical Metalloimmunoassay Based on a Colloidal Gold Label. Anal. Chem 2000, 72, 5521-5528. [PubMed: 11101226]

(40). Degregory PR; Tsai Y-J; Scida K; Richards I; Crooks RM Quantitative Electrochemical Metalloimmunoassay for TFF3 in Urine Using a Paper Analytical Device. Analyst 2016, 141, 1734- 1744. [PubMed: 26824090]

(41). Cunningham JC; Scida K; Kogan MR; Wang B; Ellington AD; Crooks RM Paper Diagnostic Device for Quantitative Electrochemical Detection of Ricin at Picomolar Levels. Lab Chip 2015, 15, 3707-3715. [PubMed: 26224395]

(42). Scida K; Cunningham JC; Renault C; Richards I; Crooks RM Simple, Sensitive, and Quantitative Electrochemical Detection Method for Paper Analytical Devices. Anal. Chem 2014, 86, 65016507. [PubMed: 24918259]

(43). Kogan MR; Pollok NE; Crooks RM Detection of Silver Nanoparticles by Electrochemically Activated Galvanic Exchange. Langmuir 2018, 34, 15719-15726. [PubMed: 30525650]

(44). Cunningham JC; Kogan MR; Tsai Y-J; Luo L; Richards I; Crooks RM Paper-Based Sensor for Electrochemical Detection of Silver Nanoparticle Labels by Galvanic Exchange. ACS Sens. 2016, 1, 40-47.

(45). Bard AJ; Faulkner LR Electrochemical Methods: Fundamentals and Applications, 2nd ed; Harris D, Swain E, Robey C, Aiello E, Eds.; John Wiley \& Sons, Inc.: Hoboken, 2001.

(46). Grubisha DS; Lipert RJ; Park H-Y; Driskell J; Porter MD Femtomolar Detection of ProstateSpecific Antigen: An Immunoassay Based on Surface-Enhanced Raman Scattering and Immunogold Labels. Anal. Chem 2003, 75, 5936-5943. [PubMed: 14588035]

(47). Mandl A; Filbrun SL; Driskell JD Asymmetrically Functionalized Antibody-Gold Nanoparticle Conjugates to Form Stable Antigen-Assembled Dimers. Bioconjugate Chem. 2017, 28, 38-42.

(48). Zhang L; Hu D; Salmain M; Liedberg B; Boujday S Direct Quantification of Surface Coverage of Antibody in IgG-Gold Nanoparticles Conjugates. Talanta 2019, 204, 875-881. [PubMed: 31357376]

(49). Anfossi L; Di Nardo F; Russo A; Cavalera S; Giovannoli C; Spano G; Baumgartner S; Lauter K; Baggiani C Silver and Gold Nanoparticles as Multi-Chromatic Lateral Flow Assay Probes for the Detection of Food Allergens. Anal. Bioanal. Chem 2019, 411, 1905-1913. [PubMed: 30397760]

(50). Yeh C-H; Chen W-T; Lin H-P; Chang T-C; Lin Y-C Development of an Immunoassay Based on Impedance Measurements Utilizing an Antibody-Nanosilver Probe, Silver Enhancement, and Electro-Microchip. Sens. Actuators, B 2009, 139, 387-393.

(51). Hermanson GT Bioconjugate Techniques, 3rd ed.; Audet J, Preap M, Eds.; Elsevier: New York, 2013.

(52). Trilling AK; Beekwilder J; Zuilhof H Antibody Orientation on Biosensor Surfaces: A Minireview. Analyst 2013, 138, 1619-1627. [PubMed: 23337971]

(53). Siriwardana K; Wang A; Vangala K; Fitzkee N; Zhang D Probing the Effects of Cysteine Residues on Protein Adsorption onto Gold Nanoparticles Using Wild-Type and Mutated GB3 Proteins. Langmuir 2013, 29, 10990-10996. [PubMed: 23927741]

(54). Tripathi K; Driskell JD Quantifying Bound and Active Antibodies Conjugated to Gold Nanoparticles: A Comprehensive and Robust Approach to Evaluate Immobilization Chemistry. ACS Omega 2018, 3, 8253-8259. [PubMed: 30087938] 
(55). Szymanski MS; Porter RA Preparation and Quality Control of Silver Nanoparticle-Antibody Conjugate for Use in Electrochemical Immunoassays. J. Immunol. Methods 2013, 387, 262-269. [PubMed: 23153725]

(56). Pollok NE; Rabin C; Smith L; Crooks RM Orientation Controlled Bioconjugation of Antibodies to Silver Nanoparticles. Bioconjugate Chem. 2019, 30, 3078-3086.

(57). Kumar S; Aaron J; Sokolov K Directional Conjugation of Antibodies to Nanoparticles for Synthesis of Multiplexed Optical Contrast Agents with Both Delivery and Targeting Moieties. Nat. Protoc 2008, 3, 314-320. [PubMed: 18274533]

(58). Bio-Rad. LYNX Rapid HRP Antibody Conjugation Kit, 2011; pp 10-11.

(59). Schellenberger U; O’Rear J; Guzzetta A; Jue RA; Protter AA; Stephen Pollitt N The Precursor to B-Type Natriuretic Peptide Is an O-Linked Glycoprotein. Arch. Biochem. Biophys 2006, 451, 160-166. [PubMed: 16750161]

(60). Røsjø H; Dahl MB; Jørgensen M; Røysland R; Brynildsen J; Cataliotti A; Christensen G; Høiseth AD; Hagve TA; Omland T Influence of Glycosylation on Diagnostic and Prognostic Accuracy of N-Terminal pro-B-Type Natriuretic Peptide in Acute Dyspnea: Data from the Akershus Cardiac Examination 2 Study. Clin. Chem 2015, 61, 1087-1097. [PubMed: 26056354]

(61). Fisher Thermo. Dynabeads MyOne Streptavidin T1 Protocol; 2016.

(62). Esteban-Fernandez de Ávila B; Escamilla-Gómez, V.; Campuzano, S.; Pedrero, M.; Pingarron,' J. M. Disposable Ampero-metric Magnetoimmunosensor for the Sensitive Detection of the Cardiac Biomarker Amino-Terminal pro-B-Type Natriuretic Peptide in Human Serum. Anal. Chim. Acta 2013, 784, 18-24. [PubMed: 23746403] 


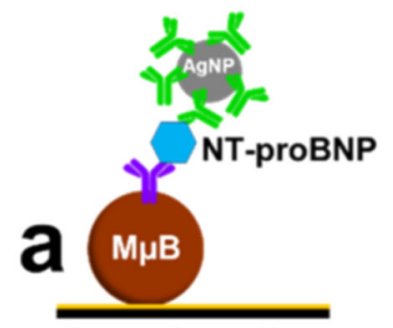

Assay formation
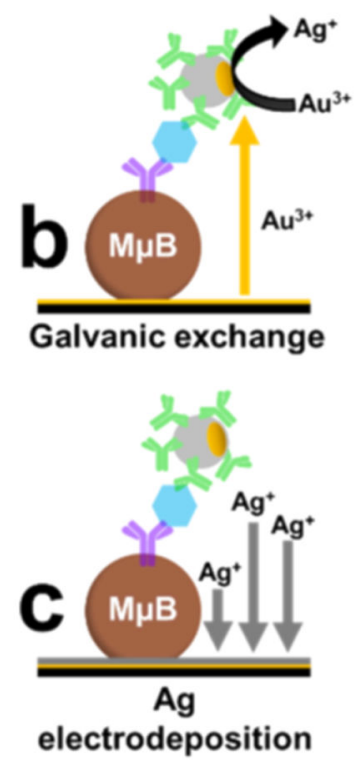

Scheme 1.

Illustration of the Galvanic Exchange Method Used to Detect Ag Following Formation of the Assay 

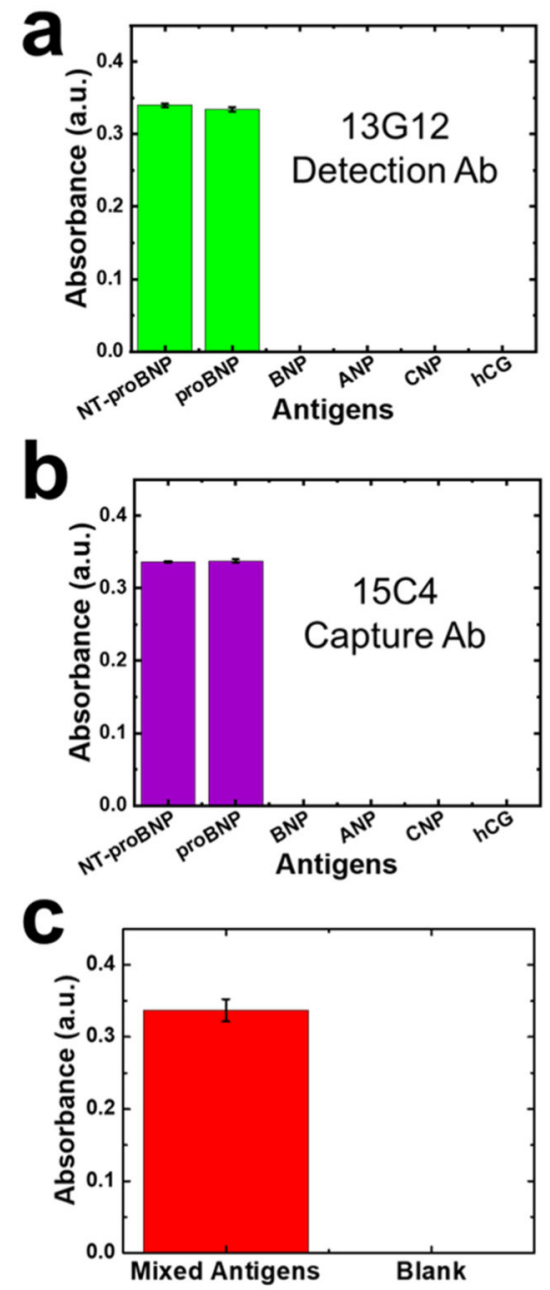

Figure 1.

Histograms representing the cross-reactivity absorbance results obtained using an indirect, half-sandwich ELISA. Results for the anti-NT-proBNP Ab pair including (a) the 13G12 detection $\mathrm{Ab}$ and (b) the $15 \mathrm{C} 4$ capture $\mathrm{Ab}$. (c) Sandwich ELISA results from the assay prepared with a mixed antigen solution containing $58.2 \mathrm{nM}$ of each of the following: NTproBNP, BNP, CNP, and ANP, prepared in $2 \%(\mathrm{w} / \mathrm{v})$ casein-PBS. The error bars represent the standard deviation of three independent measurements. 




Figure 2.

Histograms representing the amount of Ag charge obtained by forming the full metalloimmunoassay for a single concentration of NT-proBNP $(0.58 \mathrm{nM})$ using either the AgNP-Ab physisorbed conjugate or the AgNP-HBCL-Ab conjugate. The electrochemical experiment was carried out in PBS. The error bars represent the standard deviation of five independent measurements performed using five independently prepared paper electrodes. 

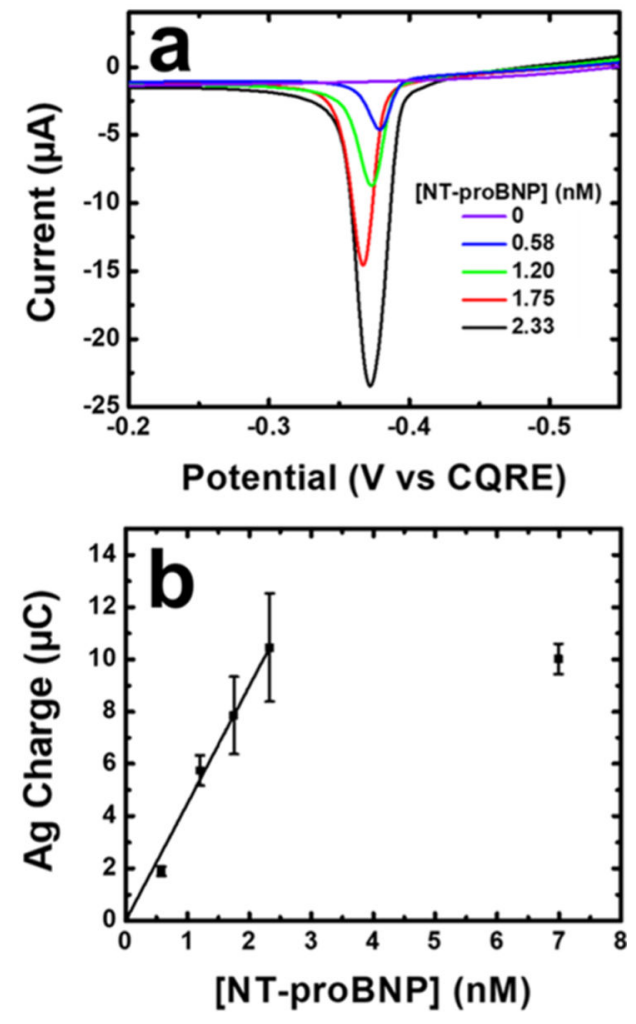

Figure 3.

Electrochemical results for detection of NT-proBNP using the full metalloimmunoassay in PBS on a paper electrode. (a) ASVs for the concentrations of NT-proBNP indicated in the legend. For clarity, only one ASV trace is shown for each concentration. The position of the ASV peaks varies slightly because of the use of a CQRE. (b) Calibration curve showing the correlation between the Ag charge [obtained by integrating ASVs like those in (a)] and the concentration of NT-proBNP. Note that for clarity, the ASV for $7.0 \mathrm{nM}$ of NT-proBNP is not shown in (a). The linear regression value is 0.99 , and the scan rate is $50 \mathrm{mV} / \mathrm{s}$. Each data point represents the average of five measurements carried out using independently fabricated electrodes. The error bars represent the standard deviation of these five measurements. Outliers were eliminated using the Grubb's test with a 95\% confidence level. 


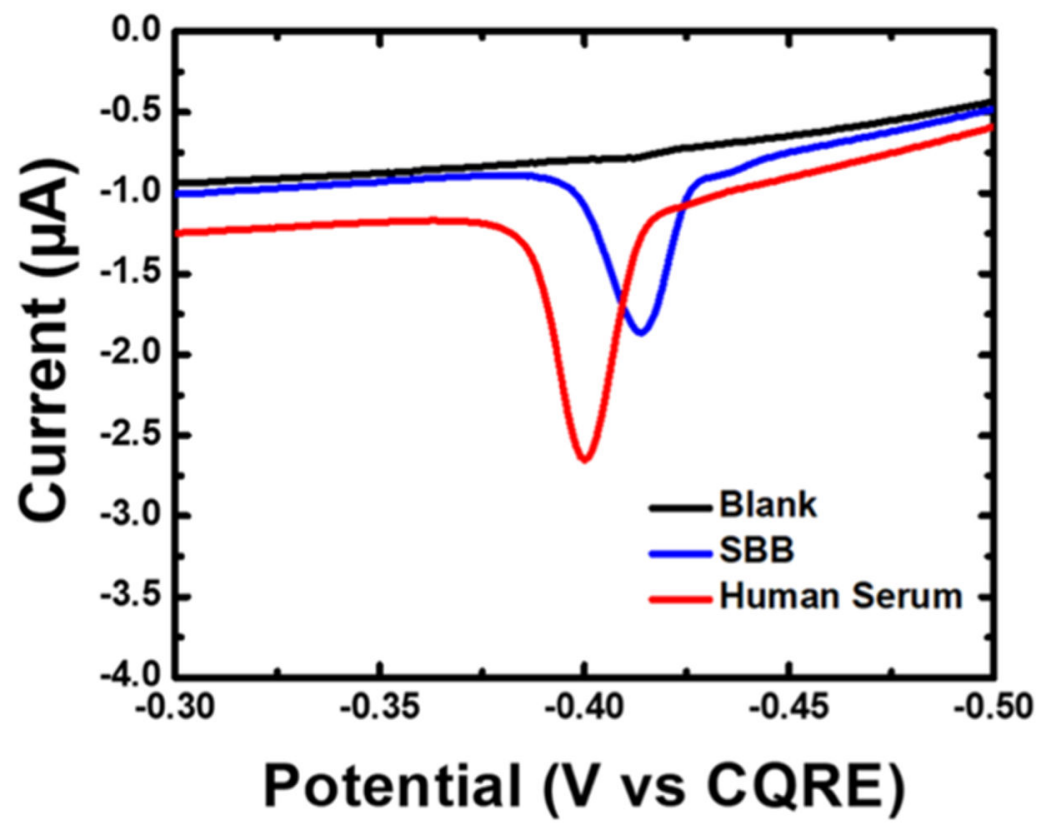

Figure 4.

ASVs obtained by forming the full metalloimmunoassay for NT-proBNP in either a SBB or an undiluted human serum matrix. The scan rate was $50.0 \mathrm{mV} / \mathrm{s}$. For clarity, only one ASV trace is shown for each conjugate, but the measurements were carried out in triplicate using independently fabricated electrodes. The position of the ASV peaks varies because of the use of a CQRE. 